\title{
The Notion of Authenticity in Multicultural Music: Approaching Proximal Simulation
}

\author{
Rohan Nethsinghe \\ Monash University \\ Australia
}

As countries become increasingly multicultural, it can be argued that the authentic teaching and learning of multicultural music in educational settings is essential. Crucial to this is the provision of cultural context to retain as much of the original meaning of the music as possible. This paper discusses the main arguments for authenticity in multicultural music and the implications for its learning and teaching. Researchers argue that the formal aspect of music transmission has been overlooked in multicultural music teaching and learning. The intention of the author is to introduce the concept of Proximal Simulation and its constituting elements, namely Authentic Performance Conventions; Authentic Audiation; Authentic Sensory Experiences and Emotions, and offer suggestions for safeguarding musical traditions through Authentic Transmission (teaching and learning) practices. This discussion also explores the qualities of the 'Transcontextualisation' theory proposed by musicologist Osamu Yamaguti in 1994, in the contexts of multicultural music performance and transmission.

\author{
Positioning Knowledge \\ Methodological Approach \\ Authentic Transmission and Pedagogical Practices \\ Conclusion \\ Acknowledgements \\ References
}

\section{Positioning Knowledge}

The notion of authenticity itself is difficult to define as it changes with the time and with the understandings of the protagonists. The authenticity of musical practices can change due to many reasons, and Lum (2009) notes that "authenticity in any music is not constant and unchanging" (p. 36). In the field of multicultural music performance and transmission, it is possible to find arguments concerning issues in authenticity discussed by many researchers from different perspectives and times. A few researchers have developed strategies to define authenticity in multicultural music education. Of the writers in this field, five have offered checklists by which teachers can ascertain the authenticity of their practice (Belz, 2006; Burton, 2002; Clements, 2006; Palmer, 1992; Tucker, 1992). Comparing these checklists and other measurements introduced by various researchers in different times reveals that they have considered a range of important aspects of authenticity in multicultural music practices. My intention is to offer fresh perspectives to inform these practices by finetuning the aforementioned checklists, utilizing existing knowledge and adding novel aspects.

Although the concepts offered in this article are not limited to a particular context or genre of music, they are mainly focused on improving strategies of 
multicultural music/world music practices, including education and transmission (teaching and learning). More than 50 years ago, Sachs (1940) articulated that world musics comprise uniformed structures that have evolved into a group of diverse branches. He further explains that with the exception of Western music other types of music ceased to develop at some point. This underpins the idea that Western music is superior to all other types of music, condemning the others as unsophisticated genres. Confirming this, Vaugeois (2009) claims, "The idea that some people are culturally unsophisticated and therefore in need of Western help is, still, very much part of the dominant discourse" (p. 12). To overcome the prevailing colonial notion of "West is the best," Campbell (2004) insisted that we should discard this "West is the best" perception, and a few years later Southcott and Joseph (2010) reiterated this idea, adding that we should "avoid tokenistic practices that may trivialize the cultures and musics of others" (p. 4).

In addition, the discussion presented in this article exploits a theory proposed by a Japanese musicologist Osamu Yamaguti in 1994 about how and when music changes. Authentic Transmission Practices also are explored in this paper in order to consider effective use of Proximal Simulation in teaching and learning world musics. Employing approaches recommended by many researchers from different countries of the world and using my own experiences, I attempt to contribute to the enhancement of practices in the field of (multicultural) music/music education and beyond. In the following discussion I introduce the elements of Proximal Simulation (Authentic Performance Conventions; Authentic Audiation; Authentic Sensory experiences and Emotions and Authentic Transmission Practices) and offer suggestions for authentic practices including teaching and learning.

\section{Methodological Approach}

This library research study conducted in the format of a literature review investigates understandings of authentic practices of multicultural music (including education) articulated by practitioners, experts, and researchers through the lenses of my experiences. The study of experiences or phenomena is termed phenomenology. Lester (1999) explains, "Epistemologically, phenomenological approaches are based in a paradigm of personal knowledge and subjectivity, and emphasize the importance of personal perspective and interpretation" (p.1). Phenomenology is used as the theoretical approach to investigate lived experiences that are interpreted through personal perspectives, and library research was employed as the main methodological approach to examine musical concepts and cultural aspects of music and music education. Campbell (2008) describes that music can be learnt formally, informally and through enculturation. I have experienced learning music via these modes described by Campbell, and knowledge acquired throughout the years as a performer will also be used in my interpretation. Education plays a prominent role in passing on cultural/traditional knowledge as countries become increasingly multicultural. Therefore, it is important to explore the importance of multicultural music education.

\section{The Importance of Multicultural Music Education}

Banks (2007) claims that "multicultural education incorporates the idea that all students regardless of their gender and social class and their ethnic, racial or cultural 
characteristics should have an equal opportunity to learn in school" (p. 3). As Australia is a multi-ethnic country, the federal government mandates multicultural practices in order to cater for those needs of diverse communities reside in the country. This situation is also found in other developed Western countries with a similar population of multicultural residents, for example the United Kingdom, the United States of America, and Canada.

Joseph and Southcott (2009a) and Forrest and Watson (2010) identified music as an effective vehicle to promote multiculturalism in schools. However, there are issues identified in the provision of multicultural music education, especially in the process of recreation/re-performance/re-production and transformation (Nethsinghe, 2012). Jan and Xiaoyun (2009) claim that "the formal aspect of music transmission has been overlooked in music education" (p. 34), and many researchers have found that this is significant in the case of multicultural music education. Jan and Xiaoyun (2009) suggest that the process of transmission should be given attention if we consider music education in schools as a form of cultural engagement. The following discussion focuses on music transmission and also considers music re-performance, which is an important aspect of teaching and learning.

\section{Contextual Changes of Musical Text}

Yamaguti (n.d.) explains that he "intended this term 'Transcontextualisation' to cover a wide range of contextual changes of musical text" (para. 2). He asserts that musical text changes in re-performance and in the process of transmission. He explains that these changes may occur in a "simple repetition of a performance of a musical composition in the same place for the same purpose but in a different time, to complicated transformations of performances done at different times at different places and for different purposes" (para. 2) and most importantly he describes that "the music texts change through transmission and diffusion in accordance with the degree of transcontextualisation applied to the original" (para. 2). Yamaguti advises that occurrences of these transformations should be fully considered "whenever we deal with strategies for safeguarding musical traditions" (para. 4). The intention of this article is to carefully consider those facts and suggest strategies for safeguarding multicultural musical traditions, especially when music is taken out from its original context for different purposes (Nethsinghe, 2012). In this process I refer to "authentic practices" of music performing and transmission offered by many practitioners/ researchers in the world, including my own experiences of music learning and teaching.

\section{Achievable Quality in Authenticity}

Blacking (1973) found that "music cannot be transmitted or have meaning without associations between people" (p. x). Confirming Blacking's finding, Palmer (1992) points out that "when a music is transferred from its original culture, it loses some of its essential qualities" (p. 32). Joseph (2010) explains that, for this reason, "it is necessary to uphold the integrity of the music when made out of its original setting" (p.70). However, it is impossible to re-create the precise original experience of a previous event due to many reasons. Young (1988) argues that even if the sounds of a work could be reproduced similarly as might have been heard at the time of its composition, re-creation of the experience of that piece shared by the composer and his or her contemporary audience is unachievable because it is impossible to reproduce the physical, social, cultural, and historical context of the time of the 
composer(s), performer(s), and audience. Costes-Onishi (2010) affirms that "it is possible to come as close to the original, but the essence...which is bound to its context, can never be captured" (p.130). As a solution for these issues in unobtainable re-creation, it is most realistic to offer a musical work that could cover most of the aspects of authenticity/originality to the maximum possibility; thus exploring the notion of proximity to the original becomes important. Burton (2002) suggests the idea of "acceptably authentic" representation of musical materials intended for classroom use, which could be considered as a similar idea developed on Tucker's(1992) authenticity check list.

There are three elements of authenticity identified in achieving what will be termed as "Proximal Simulation," and they are applicable for performances as well as written material. The word proximal is adopted from "the zone of proximal development" (ZPD) by Vygotsky (1978); it is the most suitable word to use in this situation because it provides the idea of closeness to the original in reproduction. An authentic presentation of a musical work would ideally be a perfect imitation of a performance (of song and/or music) in order to reproduce a very similar phenomenon to the genuine original in its original setting by the original performers. This could be identified as an adjacent Proximal Simulation. This idea will be discussed under three headings: Authentic Performance Conventions, Authentic Audiation, and Authentic Sensory experiences and Emotions.

\section{Authentic Performance Conventions}

Davies (2003) claims that "the authentic performance movement is a phenomenon of the last fifty years" (p. 60). In his book titled Themes in the Philosophy of Music, Davies (2003) discusses authenticity in music, particularly in the case of the Western cultural tradition, but the facts he introduced in his book can be successfully applied to the question of the authenticity of multicultural music (p. 81). Considering the issue of authenticity, Palmer (1992), writing of music education in America, points out that songs from around the world have been placed in textbooks with texts translated and sometimes altered to fit local national concepts. If this is done, the authenticity of the piece can be seriously affected when performed, and it would no longer bear the characteristics of the original. In order to avoid such consequences, Tucker (1992) and Burton (2002) recommend consulting a musician from within the relevant culture in the preparation of materials. Reflecting the current global trends, Costes-Onishi (2010) points out that "when situated within the phenomena of transnational movements of people and swift exchanges between cultural practices, it becomes impossible to adhere to a fixed definition of what are authentic and traditional without essentializing the culture bearers or 'ethnic artists'" (p. 111).

There are more components to a performance that just the music. There can also be dance, related games, stagecraft, costumes, and many other such important aspects of a whole performance. A similar presentation to the original including the simulation of other (aforementioned) aspects is the next important feature of a performance. Tucker (1992) explained that if we change the cultural context and musical style in which music is presented we may remove much, if not all, of its meaning; thus it is essential to maintain the authenticity of related movements. Simulation of costumes, backgrounds, place of performance, and all other parameters a person can see in a performance are also important in the generation 
of an authentic experience. Digitally or electronically captured/recorded information also should represent the authentic experience featuring the above mentioned qualities of a performance. Lum (2009a) revealed teaching world music through feature films as an effective approach, suggesting that "feature films can bring a plethora of visual and aural stimulation to students and enhance their learning" ( $p$. 71). Yamaguti (n.d.) revealed that "recording a performance on tape or disc has become increasingly important in the course of twentieth century" (para. 4). Green (2008) points out that "enculturation or immersion in the music and musical practices of one's environment is a fundamental factor that is common to all aspects of music learning whether formal or informal" (p. 5). Gorfinkel (2010) suggests that "CDs, video and television could provide an experience of 'immersion' for students" (p. 47). Extending this idea, Burton (2002) proposes that "recordings of the musical materials should be provided as models for performance" (p. 165). In guidelines for meaningful authentic multicultural music experiences, Belz (2006) also suggests that "highquality visuals should be used" in presentations (p. 45).

Davies (2003) explains that "it is a necessary condition of a musical work's being a transcription that it be intended as such" (p. 47). He further explains that if a musical score is a transcription of a music piece it must be the intention of the producer of the score to write a work faithful to the musical content of original musical work. In some cases it is possible to find musical works transcribed regardless of the facts explained above, and this can be identified as an issue that affects the authenticity of the original musical work or composition. It is important to highlight the fact that most of these problems occur in transcribing musics of different styles or cultures into traditional Western music notation. Davies (2003) argues that "an ideally authentic performance is a performance that is faithful to what is determined in the musical notation according to the conventions appropriate to the interpretation of that notation" (p. 54). He further explains that "a performer can best attempt to realize the composer's musical ideas by rendering the score faithfully" (Davis, 2003, p. 55). This assumes the internationality of the score itself.

Some composers write aleatoric or chance music in which some elements of the performance are left to chance. Other composers frequently allow room for performer interpretation. No matter what method they use, it is essential to maintain the originality by following those genuine methods practiced by a culture or intended by composers. There are other ways of presenting musics employed by many different cultures, for example orally and aurally transmitted and learnt presentations and improvisations. According to Davis (2003), any musical works can be performed in a variety of different ways, and authentic performance practice places emphasis on the understanding of the characteristics of performance employed during the composer's lifetime, those actually envisioned by the composer, or those which the composer might have known or experienced. Quesada (2002) pointed out that "many styles of world musics are transmitted by oral tradition and consequently, a system of notation may not have been developed by the practitioners of the style" (p. 153). Kwami (2001) points out that "there is no written form of notation in black African music; the music literacy that operates in black African communities is transmitted and propagates through aural-oral means" (p. 144) and confirming this, Joseph (2010) claims that "indigenous African methodology of learning is through practical music experiences and creativity" (p. 71). Therefore, it is always important to employ the same methods and practices used in a culture of origin. Assuming the availability 
of above mentioned resources and knowledge of practice, the next step will be to consider how to perform authentically.

Exploring the issue of what could be an authentic performance from another perspective, Nettl (1983) claimed that the only constant in life is change and there will always be interaction between people of different cultures and the music that they make; thus there will always be new and different interpretations of traditional and contemporary music. As a solution to this problem of authentic performance and repertoire, Volk (2002) recommends consulting a culture bearer who is a practicing musician in that culture or a researcher known to have experience in that particular culture and its music.

\section{Authentic Audiation}

Audiation is a word coined to explain the nature of listening vocabulary in music. The word means "the ability to hear and to give meaning to music" (Gordon, 2005 , p. 11). This element explores the proper knowledge of lyrics, the background of a musical work including information about composer(s), performer(s), and cultural context/practice, plus the knowledge of historical, geographical, and philosophical contexts. Yamaguti (n.d.) defines this as the musical context referring to "the situation that surrounds and sustains the existence of the text, for example, the human body, musical instruments, socio-cultural background of performing arts, etc." (para. 1). Green (1988) found "musical meaning to be both musically and culturally bound" ( $p$. 34); thus it is important to acquire knowledge of the music and its cultural practice (Blacking, 1967,1995; Campbell, 2001; Nettl, 1983). To this Volk (2004) rightly expressed the idea that "the greater the knowledge one has about the culture, and the expectations or rules of its music, the greater the understanding or perception of meaning of that music will be" (p. 6).

Use of appropriate instruments is the next effective aspect in this process, including instrumentation and arrangement of a musical work plus simulating the original voice(s) if it is a song. Davies (2003) argues that change or an addition of an accompaniment/ instrumentation that was originally not arranged or composed for a particular piece of music will affect the authenticity of the original. Use of the original language with correct pronunciation is also an important fact, and McCulloughBrabson (1995) suggests for successful teaching of music from another culture it is important to use the original language and, if necessary, to provide the translation where possible. Maintaining proper presentation of parameters and elements of music such as rhythm, timbre, texture, tone color, dynamics, and musical form is vital; Davies (2003) highlights the importance of securing these qualities in order to retain the authenticity of a musical work.

Consideration of traditional and contemporary types of music of a culture is a continuous issue, and Belz (2006) points out that "cultures are dynamic and evolving"; therefore, it is important to present contemporary as well as traditional music (p. 45). In this matter of re-producing the original sound (of the past), the use of technology and equipment also plays a major role. For example, guitarists still use amplifiers with valves (or tubes) to generate the authentic sounds of rock music in the Sixties, and many musicians use modern samplers and synthesizers to imitate sounds of different (traditional) instruments. 


\section{Authentic Sensory Experiences and Emotions}

Authentic Sensory Experiences and Emotions represent the feelings derived from senses in humans. Nassbaum (2001) claims that "emotions shape the landscape of our mental and social lives" (p. 1). She argues that, if a cognitive/ evaluative theory of emotions is correct and if emotions could be considered as essential elements of human intelligence, these claims provide strong reasons to promote the conditions of emotional well-being. Nassbaum (2001) continues to argue that "without emotional development a part of our reasoning capacity will be missing" (p. 3). This view holds that emotions are "appraisals of value judgments thus containing the idea of a cognitive appraisal or evaluation" (Nassbaum, 2001, p. 4). Therefore, it is essential to provide an authentic sense of emotions in a performance as emotions evaluate a phenomenon through a cognitive process (Juslin \& Sloboda, 2006). Hallam (2010) identifies the importance of sensitivity to emotions suggesting that "identification of emotion in music performance draws on some of the same skills that make up everyday emotional intelligence" (p. 20). Davies (2003) also highlights the importance of the appreciation of emotions in understanding the meaning of a musical work, stating that "in describing the emotions expressed in music one is led to describe the course of the music and the experience of its connectedness" ( $p$. 123). Schippers (2006) acknowledged this, stating, "Others might argue the key to authenticity lies in the aesthetics and emotional affect" (p. 337). Although emotional affect is not the only key factor considered in defining authenticity in multicultural music, this article reinforces the importance of sensory experiences and emotions connected to musical experiences that trigger specific/authentic memories.

If an audience can sense and feel what was felt by the people from a particular culture watching a transformative performance, this obtained phenomenon by the audience can be identified as an Authentic Sense of Emotions. Blacking (1973) explained the importance of feelings about music in knowing "what music is." $\mathrm{He}$ points out that structural factors of music generate feelings, and the analysis of musical structures is the first step toward understanding musical process; hence, knowing musical structures will help to understand "what music is." Properly understanding "what music is" from a particular culture can be defined as having authentic knowledge. Blacking (1973) articulates that "we may never be able to understand exactly how another person feels about a piece of music, but we can perhaps understand the structural factors that generate the feelings" ( $p$. 26). Thus presenting structural factors that generate authentic feelings is vital in a performance. Members of particular cultures may have an established understanding of meaning embedded in musical gestures and conventions.

\section{Sense of Smell, Mood/Feelings and Feel of Time}

Explaining an aesthetic experience from a referentialist perspective, Younse (2004) explained that "the meaning and the value of a work of art lie beyond the work of art itself in concepts such as socio-cultural aspects surrounding the music, biographical information about the composer or the story in a programmatic work of music" (p. 129). Younse (2004) explains, "The concept of expressionism refers to the idea that the artwork is intimately with feelings or with subjectivity" (p. 130). Describing the concept of referentialism, Reimer (2009) noted that "whether the meanings of music are designated by its words, or by its stipulated or interpreted programs, or by its association with cultural events or artifacts or practices, 
referentialism proposes that musical experience be conceived, at least largely if not entirely, as the recognition of such meanings and their incorporation as an essential ingredient in one's experience" (p.80). Blacking (1973) argues that "people's classifications of songs by form and by function may provide important evidence of musical and transformation that are acceptable in a culture" (p.43). He further explains that such evidence may explain both the structure and effect of the music. As examples for the function of songs it is possible to identify Sri Lankan harvest songs, cultivation songs, and fishing songs sung in a particular time of the year to accompany a particular task. For example, there are songs to accompany the harvesting of rice in the paddy fields in March and April during the Sinhalese New Year season when it is hot, and there are songs to accompany planting of rice when it is raining and cold. Further there are songs that include rhythms that support the work of fishermen while dragging nets to the beach in Sri Lanka. Thus, different songs remind me about a particular function carried out in a particular time of the yearly cycle. Most of the folk songs in Sri Lanka are directly related to the passing seasons in some way. While maintaining my Sri Lankan culture but studying in a very different place, it did not seem appropriate to perform a Sri Lankan New Year song, traditionally sung in hot weather, when attending New Year celebration (during the winter) in Ukraine when there was snow all around. In a performance evoking a culture, it is essential to consider these discussed elements of authenticity.

According to Kaufmann (1968) rāgas of Indian classical music are prescribed to be performed at a set time of the day or season with the intention of evoking specific moods within the listener, for example Kalyan 7-10 a.m. and Purvi 4-7 p.m. Some of the rāgas are used in ritual performances, which can enhance the evocative power of the music. Highlighting a very important prospective of mood, Belz (2006) suggests that "sacred and secular material should be presented appropriately and with sensitivity" (p. 45). This could include presentation of rituals to create the appropriate atmosphere.

My own experience provides a valid example for this phenomenon. Two major religions influenced me when I grew up. My father was a Methodist, and I used to visit the church and attend the Sunday school guild in the evening to learn Christianity. As my mother is a Buddhist, I studied Buddhism at school and in Sunday mornings attended the Buddhist religious school. During the main Buddhist festival season in May (to celebrate the Birth, Enlightenment, and the Nirvana of Lord Buddha) we sang Buddhist songs similar to Christmas carols, wearing white (Sri Lankan National dress) with coconut oil lamps on our palms, in the temple where a lot of incense sticks were lit. During the Christmas season (in December) we sang Christmas carols in English, wearing colorful clothes. Even though these activities sound similar, the experiences were totally different. During the Buddhist festival, I had a sad feeling with the associated smell of oil lamps and incense sticks, and the music generated a calming/sad mood when performed in the hot month of May. The Christmas carol experience was the opposite. It was colorful and happy (with movements) performed in December when the climate is much cooler in Sri Lanka. These differences of feeling and mood of two different types of multicultural/religious music performances differentiate my memories, and they both contain unique authentic qualities.

Therefore, it is not just the mood and the sound that can be evocative. In 2008 de Carteret, Somerville, and Devos claimed that remembered images, smell, or touch open the traces or memories of past experiences through sensory experiences and emotions. For instance, the Sri Lankan harvest songs are associated with the smell of 
hay and (rice) paddy, and fishing songs are associated with the smell of ocean/river and (fresh water or salt water) fish. These songs can be categorized as function songs and recall the memories of past experiences. Furthermore, sensory impacts can be associated with different genres of music as shown by my own experiences singing in the temple and church. These transformative events are infrequent; when they do occur, however, they are both evocative and memorable. The power of music to recall/recreate vivid memory of experiences and moods is undeniable, but the question is how to recreate this to some degree in music teaching and learning. Joseph and Southcott (2010) emphasize that the lack of authenticity in teaching and learning precludes meaningful engagement; thus, these aspects of authentic pedagogical practices and learning will be reviewed below.

\section{Authentic Transmission and Pedagogical Practices}

\section{Teaching}

Tucker (1992) argues that "in teaching multicultural arts education, there must be an authentic voice in the development of what could be an effective pedagogy" ( $p$. 38). In the field of multicultural music teaching, it is not only the music itself that must be presented authentically; pedagogical practices vary between cultures and these too should be recogniced by educators. Blair and Kondo (2008) recognised the importance of authenticity in teaching multicultural music in different dimensions. Answering the question, "When teaching music of one culture to members of another, whose culture should be honoured?" they point out that "teaching practices must be authentic to the people whose music we are teaching, but it is also important that it be authentic to the students we are teaching" (p. 50).

Schippers (2006) claimed that "almost all music is transmitted out of context" (p. 347). Therefore, it is important to employ similar pedagogical approaches practiced at the original context: the "context of the transmission process" (Schippers, 2006, p. 344). Volk (1998) points out that the issue of authenticity comes into question "when considering that the very act of transferring music out of its cultural context and into the classroom destroys its authenticity" (p. 9). Several years later Volk (2002) points out further issues in multicultural music education such as transformation, teaching methodologies, repertoire, and authenticity. Teachers often face the problem of what type of repertoire should be selected in teaching. Volk (2002) advises on finding a balance between an old music culture and a contemporary one, stating that "teachers must always remember that music is dynamic within its culture, growing and changing with its society" (p. 22). The issue of authentic practice in teaching of music from diverse cultures is another important one. Volk (1998) points out that "authenticity of music education was not a particular concern in the past, but suddenly it became an issue with the advent of music education's awareness of world musics combined with the general tenor of recent times regarding sensitivity for all peoples" (p. 177).

When a musical work is filtered through the qualities of Proximal Simulation, it is possible to practice authentic transmission methods explored and expected by experts in the field, as described in the beginning of this paper. The use of proper teaching material and pedagogies including traditional methods of teaching that belongs to a particular culture (like oral and aural methods) is highly important. Kwami (2001) emphasizes the need of authenticity when transmitting "another music" 
and advises teachers to employ proper teaching techniques. To further confirm the authenticity, a cultural insider should attest to the authenticity of "teaching material" (Belz, 2006, p. 45). Merriam (1964) states that "we should work to evaluate anything from the perspective of the people who created it and that can be applied not only to music as object, but to the methods by which music is transmitted between people" (p. 31). Strengthening this statement, Hildegard and Anundsen (2006) point out that "every musical practice and music culture contains a way to teach music" (p. 62). Therefore, it is important to use the genuine teaching methods practiced by a culture to retain the authenticity of the musical work. Dunbar-Hall (2002) suggests that teaching strategies should reflect "multicultural ideologies such as different methods of transcribing and notating music" (p. 62). Green (2008) explains that in some folk and transitional musics such as Indian classical music and to a large extent in jazz there are systems of "apprenticeship training" whereby young musicians are introduced, trained, or just helped in general by expert musicians. Green (2008) claims that "in such environments older [expert] musicians might provide specific guidance" and "act as expert musical models whom learners can talk to, listen to, watch and imitate" (p. 6). My prior experiences confirm that apprenticeship training as a hybrid of authentic music teaching and learning through my prior experiences.

\section{Learning}

Southcott and Joseph (2009b) point out that we can transform our understanding of learning by engaging with music from other cultures. Thus it is essential to employ proper learning methods in learning world musics. Learning an authentic musical work in an authentic manner involves many different aspects. Green (2008) points out that in some traditions music is learnt by watching, imitating, and listening to music making. Following instructions, learning through observations and engagement, learning from written material (musical scores) and other methods such as video schools and (sound) recorded material are examples. If it is a written piece of work, the transcript needs to be authentic, and if it is a performance or a demonstration, the performer (or the instructor) needs to include the aforementioned elements and components of authenticity in the performance.

A commonly accessible way of learning or performing different musics is the use of the written notation of a particular music work, in other words use of a musical transcription. According to Davies (2003) interpretation of a composer's work recreated faithfully by the composer him/her self or by another person is a transcription of a musical score. This process of interpretation affects on the authenticity of an original music work (Nethsinghe, 2012). Therefore, it is important to minimize these changes employing Proximal Simulation.

Joseph (2010) points out the use of mnemonics in African communities as a useful methodology of learning "when either demonstrating or teaching through imitation" (p. 71). Such hands on'/experiential learning is the same method practiced in my Sri Lankan culture, for example, in learning traditional drumming (where the learner has to imitate the teacher's actions). Developing John Dewey's idea of learning through doing, Elliott (2005) and Belz (2006) point out that active engagement in learning multicultural music provides an authentic experience.

The involvement of experts/specialists including culture bearers in performing, demonstrating, and teaching is highly recommended to deliver an effective learning experience through authentic practices employed in a culture. Clements (2006) 
argues that an authentic reproduction is possible to achieve through the use of culture bearers. Highlighting the engagement of people from within a culture in the process of transmission, Nethsinghe (2009a) argues that "it is not possible for the school structure to cater for all different cultural needs of multicultural communities [in Victoria], [so] each community has to do their duty by providing such opportunities for the future generation to achieve these objectives" (p. 27).This argument demonstrates the value of the involvement of people/experts from within a culture in the process of retaining their cultural authenticity. Moran and Hakuta (1995) found that "each member of a community brings a wealth knowledge to the learning environment" (p. 458). Exploring the employment of artists as experts/specialists, Nethsinghe (2009b) points out that "visiting artists [and artists in residence] can be invited to be involved in the process of teaching" (p. 81). Southcott and Joseph (2009c) found "inclusion of artists-in-schools to be an intriguing, engaging and authentic way for school pupils and their teachers to engage with music of diverse cultures" (p. 20).

Interdisciplinary music learning is another method explored by the experts. This term interdisciplinary music learning was used by Southcott and Joseph (2006). McCullough-Brabson (2002) argues that music should not be considered "as a subject to be taught in isolation from context" (p. 126). Strengthening this argument Belz (2006) points out that "presenting multicultural music through integration with other disciplines may lead to more meaningful experiences for students" (p. 45). Considering the outcomes, Ellis and Fouts (2001) point out that "an interdisciplinary curriculum improves high-level thinking where learning is less fragmented and students are provided with a more unified sense of process and content" (p. 24).

Finally it is important to mention that this notion of Proximal Simulation can also be used in different disciplines/fields such as language education, as well as in music or arts fields. Use of culture bearers/native speakers of a particular language is considered as the most effective method to teach a language authentically in a foreign environment for people from another (cultural) background.

\section{Conclusion}

This paper links knowledge from different times and contexts and from a range of prospects by numerous researchers and practitioners that need analysis at different levels of abstraction. This approach was used as a tool to harvest and harness existing knowledge and to develop a fresh perspective, also utilizing my knowledge and experiences contributing to the process of knowledge production and scholarship in the field of multicultural music/music education. The model of Proximal Simulation is intended to stimulate and cater for all human senses such as vision, hearing, smell, and touch, all of which are used to take in information from different sources for different purposes such as acquiring knowledge, entertainment, and creativity. Three elements (Performance Conventions, Authentic Audiation and Authentic Sensory Experiences and Emotions) encompassing the senses could be used to simulate authentic practice in multicultural music and its transmission (learning and teaching). It is also important to approach Proximal Simulation in different performance contexts to attempt authenticity or as much authenticity as possible. Schippers (2009) points out that music from other cultures can be recontextualised and taught quite successfully in different (educational) settings employing appropriate strategies. The perspective of Proximal Simulation can be 
defined as a suggestion for this purpose and as a method of gauging the degree of transcontextualisation that can be applied to an original musical work in order to safeguard multicultural musical traditions through authentic practices. In the notion of approaching authenticity in (multicultural) music re-performance/re-production and education, the closer the proximal simulation achieved through stimulation of human senses, the better the authenticity. Ultimately all attempts at authenticity can be identified as a matter of respect and trustworthiness of the source. Campbell (2002) claims that "authentic musical experiences depend more on the trustworthiness of the source" (p. 207). If a person truthfully respects the values of other musics and cultures, this is the first step to Proximal Simulation.

\section{Acknowledgements}

I would like to thank my PhD supervisor, Associate Professor Jane Southcott, for her continued support and advice in writing this paper.

\section{References}

Banks, J. A., \& Banks, C. A. M. (Eds.). (2007). Multicultural education, issues and perspectives $\left(6^{\text {th }}\right.$ ed.). Hoboken, NJ: John Wiley \& Sons.

Belz, M. J. (2006). Opening the doors to diverse traditions of music making: Multicultural music making at the university level. Music Educators Journal, 92(5), 42-45.

Blacking, J. (1973). How musical is man. Seattle, WA: University of Washington Press.

Blacking, J. (1995). Music culture and experiences. Chicago, IL: The University of Chicago Press.

Blair, D., \& Kondor, S. (2008). Bridging musical understanding through multicultural musics. Music Educators Journal, 94, 50-55.

Burton, B. (2002). Weaving the tapestry of world musics. In C. A. Jones (Ed.), World musics and music education: Facing the issues (pp. 161-186). Reston, VA: The National Association for Music Education.

Campbell, P. S. (2001). Unsafe suppositions? Cutting across cultures on questions of music's transmission. Music Education Research, 3(2), 215-226.

Campbell, P. S. (2002). In study of expressive cultures: The pathway of a white middle-class music teacher. In C. A. Jones (Ed.), World musics and music education: Facing the issues (pp. 239-258). Reston, VA: The National Association for Music Education.

Campbell, P. S. (2004). Teaching music globally. New York, NY: Oxford University Press.

Campbell, P. S. (2008). Musician and teacher: An orientation to music education. New York, NY: Norton \& Company.

Clements, A. C. (2006). Across cultural boundaries: Sharing cultural knowledge through music with the use of culture bearers. Retrieved from http://www. drama.org.nz/?p=255 
Costes-Onishi, P. (2010). Kulintang stateside: Issues on authenticity of transformed musical traditions contextualized within the global/local traffic. Humanities Diliman, 7(1), 111-139.

Davies, S. (2003). Themes in the philosophy of music. New York: Oxford University Press.

de Carteret, P., Somerville, M., \& Devos, A. (2008). A collective biography of place, Refereed Conference Proceedings, AARE Annual Conference 2008, Brisbane, Australia.

Dunbar-Hall, P. (2002). The ambiguous nature of multicultural music education: Learning music through multicultural content, or learning multiculturalism through music? In C. A. Jones (Ed.), World Musics and Music Education: Facing the Issues (pp. 161-186). Reston, VA: The National Association for Music Education.

Elliott, J. D. (2005). Introduction. In J. D. Elliott (Ed.), Praxial music education. New York: Oxford University Press.

Ellis, A., \& Fouts J. (2001). Interdisciplinary curriculum: The research base. Music Educators Journal, (March), 22-26, 68.

Forrest, D., \& Watson, A. (2010). Harmony through values education in Australia. In W. L. Sims (Ed.) Proceedings of the XIX World Conference of the International Society for Music Education. Beijing.

Gorfinkel, P. (2010, 11-13 January). Pushing the boundaries of 'music': Cultural and cross-disciplinary possibilities for 'other' musics in the Australian music classroom. Paper presented at the Tenth International Conference on Cultural Diversity in Music Education, Sydney, Australia.

Green, L. (1988). Music on deaf ears. Manchester, UK: Manchester University Press.

Green, L. (2008). Music informal learning and the school: A new classroom pedagogy. Aldershot, UK: Ashgate Publishing Limited.

Hallam, S. (2010). The power of music: Its impact on the intellectual, social and personal development of children and young people. Retrieved from www.ioe.ac.uk/Year_of_Music.pdf - 2010-05-06

Hildegard, K., \& Anundsen, T. W. (2006). Is there a Swahili way of teaching music? In M. Mans (Ed.), Centering on African practice in Musical Arts Education (pp. 6174). Johannesburg, South Africa: African Minds.

Jan, C. C., \& Xiaoyun, L. (2009). Forms of music transmission in music learning and their related factors: As observed through the case of shape learning in University. Putra, Malaysia.

D. Hong (Eds), 7th Asia-Pacific symposium on music education research (pp. 115). Shanghai, China: International Society of Music Education Asia Pacific Regional Conference Proceedings.

Joseph, D. (2010, 11-13 January). Music needs no visa: Insights from three South Africa voices on teaching African music in Melbourne, Australia. Paper presented at the Tenth International Conference on Cultural Diversity in Music Education, Sydney, Australia. 
Juslin, P., \& Sloboda, J. (2006). Music and emotion, theory and research. New York, NY: Oxford University Press.

Kaufmann, W. (1968). The Ragas of North India, Calcutta, India: Oxford and IBH Publishing Company.

Kwami, R. (2001). Music in and for a pluralist society. In C. Philpott \& C. Plummeridge (Eds.), Issues in music education, (pp.142-155), London, UK: Routledge-Falmer.

Lum, C. H. (2009). An historical perspective on the Chinese Americans in American music education. Research in Music Education, 27, 27-37.

Lum, C. H. (2009a). Teaching world music through feature films. Music Educators Journal, 95(3), 71-75.

McCullough-Brabson, E. (1995). Music and cultural diversity: Thoughts from a world music cheerleader. In S. Stauffer Ed.), Toward tomorrow: New visions for general music (pp. 75-80). Reston, VA: MENC.

McCullough-Brabson, E. (2002). Passing the cultural baton of music. In C. A. Jones (Ed.), World musics and music education: Facing the issues (pp. 119-138). Reston, VA: The National Association for Music Education.

Merriam, A. (1964). The anthropology of music. Chicago: University of Chicago Press.

Moran, C., \& Hakuta, K. (1995). Bilingual education: Broading research perspetives. In J. A. Banks, \& C. A. M. Banks (Eds.), Handbook of research on multicultural education (pp. 445-464). New York, NY: Macmillan Publishing.

Nassbaum, M. (2001). Upheavals of thought the intelligence of emotions. New York, NY: Cambridge University Press.

Nethsinghe, R. (2009a). To the land of the tea trees from the island of tea: A learning experience in performing arts for children of Sri Lankan community in Melbourne. Victorian Journal of Music Education, 1, 3-12.

Nethsinghe, R. (2009b). Finding balance in a mix of culture: How Sri Lankan/Australian students use music in their construction of self identity in multicultural Australia. Faculty of Education. Melbourne, Monash University. Unpublished thesis, Honours Degree in Bachelor of Education: i-95.

Nethsinghe, R. (2012). Attaining proximal simulation in multicultural music education. Faculty of Education. Melbourne, Monash University. Unpublished thesis, Doctor of Philosophy: i-361.

Nettl, B. (1983). The Study of ethnomusicology. Urbana, IL: University of Illinois Press.

Palmer, A. J. (1992). World music in music education: The matter of authenticity. International Journal of Music Education, 19, 32-40.

Reimer, B. (2009). Seeking the significance of music education: Essays and reflections. Lanham, MD: Rowman and Littlefield Education.

Schippers, H. (2006).Tradition, authenticity and context: The case for dynamic approach. British Journal of Music Education, 23(3), 333-349. 
Schippers, H. (2009). Facing the music. New York, NY: Oxford University Press.

Southcott, J., \& Joseph, D. (2006). Multiculturalism in arts education: Engaging schools in effective and authentic pedagogies. Australian Association for Research in Education. AARE Conference 2006. Retrieved from http://www.aare.edu.au/06pap/code.06.htm

Southcott, J., \& Joseph, D. (2009b). Pre servise Australian music educaotrs: An umbrella of cultural understandings. The 7th Asia-Pacific symposium on music education research (p. 13). Shanghai, China: Shanghai Conservatory of Music.

Southcott, J., \& Joseph, D. (2009c). Engaging, exploring and experiencing multicultural music in Australian music teacher education: The changing landscape of multicultural music education. Journal of Music Teacher Education 20(1), 8-26.

Tucker, J. (1992). Circling the globe: Multicultural resources. Music Educators Journal, 78(9), 37-40.

Volk, M. T. (1998). Music education and multiculturalism: Foundations and principles. New York: Oxford University Press.

Volk, M. T. (2002). Multiculturalism: Dynamic creativity for music education. In C. A. Jones (Ed.), World musics and music education: Facing the issues (pp. 1529). Reston, VA: The National Association for Music Education.

Volk, M. T. (2004). Music, education and multiculturalism. Oxford, UK: Oxford University Press.

Vygotsky, L. S. (1978) Mind in society: The development of higher psychological processes. Cambridge, MA: Harvard University Press.

Yamaguti, O. (n.d.). Proposal for a tripartite theory (Transformation / Transcontextualization / Transposition) and its application to the empowerment of an East Asian court music network with emphasis on the Vietnamese case. Retrieved from http://www.folklife.si.edu/resources/unesco/yamaguti.htm

Younse, S. (2004). Dialogic interactionism: The construction of self in the secondary choral classroom. Doctoral dissertation, University of North Texas. Retrieved from http://digital.library.unt.edu/ark:/67531/metadc4557/m2/1/high_res_d/ dissertation.pdf 